\title{
SISTEM PAKAR KERUSAKAN MOTOR KENDARAAN RODA DUA JENIS YAMAHA MATIC PADA REZA JAYA MOTOR SAMARINDA
}

\author{
Ekawati Yulsilviana $^{1)}$, Hafiz Ansari ${ }^{2)}$ \\ ${ }^{1}$ Jurusan, Manajemen Informatika, STMIK Widya Cipta Dharma Samarinda \\ ${ }^{2}$ Jurusan, Teknik Informatika, STMIK Widya Cipta Dharma Samarinda \\ ${ }^{1,2}$ Jl. M. Yamin, No. 25, Samarinda, 75123 \\ E-mail : ekawati_stmik@yahoo.com ${ }^{1)}$,hafira_21@yahoo.com ${ }^{2)}$
}

\begin{abstract}
ABSTRAK
Tulisan ini memuat bagaimana melakukan diagnosa kerusakan pada motor Yamaha matic dengan menggunakan metode Forward Chaining dan Certainty Factor Sebagai tolak ukur tingkat kepercayaan dari sistem.

Forward Chaining sebuah metode Pencocokan fakta atau pernyataan dimulai dari bagian sebelah kiri. Dengan kata lain, penalaran dimulai dari fakta terlebih dahulu, lalu dicari rule yang sesuai dengan fakta - fakta dengan menginputkan dari macam kerusakan, ke fakta Gejala yang dirasakan pengguna untuk menguji kebenaran hipotesa sehinggga menghasilkan sebuah atau beberapa solusi.

Metode pengembangan sistem yang digunakan pada tulisan ini menggunakan waterfall. Adapun langkah - langkah dari waterfall itu sendiri yaitu: Kebutuhan Sistem, Spesifikasi Kebutuhan Sistem perangkat lunak, Design perangkat lunak, Implementasi perangkat lunak, Uji mesin formal, operasi dan perawatan sistem. Metode pengujian yang di gunakan di dalam tulisan ini menggunakan white box dan Black box.

Aplikasi yang dikembangkan digunakan untuk mengetahui gejala-gejala kerusakan dan mencari solusi yang tepat terhadap kerusakan yang dialami terhadap kendaraan roda dua jenis Yamaha merk mio soul pada Reza Jaya Motor Samarinda, agar teknisi dapat mengetahui segaja jenis kerusakan terdapat kendaraan yang masuk untuk diservice atau diperbaiki.
\end{abstract}

Kata Kunci: Sistem Pakar, Forward Chaining, Diagnosa Kerusakan Motor.

\section{PENDAHULUAN}

Pada saat ini, alat transportasi sudah jelas menjadi kebutuhan yang amat mendasar. Sudah banyak orang orang menggunakan alat transportasi untuk melakukan aktivitasnya sehari-hari, mobilitas hampir tidak mungkin dilakukan jika tidak menggunakan alat transportasi. Berbicara alat transportasi, ada beberapa macam alat transportasi yang ada di Indonesia diantaranya alat transportasi darat, laut, dan udara. Dari ketiga macam alat transportasi tersebut, alat transportasi daratlah yang sering dijadikan pilihan masyarakat untuk mobilisasi. Oleh karena itu, di Indonesia alat transportasi darat sangat berkembang pesat. Buktinya adalah meningkatnya penjualan motor sebesar $50 \%$ dalam waktu satu bulan. Alasannya adalah karena motor lebih murah, rendah biaya perawatan, serta dengan dimensi yang tidak begitu besar, menjadikan sepeda motor sangat cocok digunakan di Daerah yang notabene sering terjadi kemacetan lalu lintas.

Meningkatnya kendaraan Roda Dua ini, secara tidak langsung telah membuka lahan baru untuk pekerjaan dalam bidang perbengkelan, banyak bengkel - bengkel motor dan mobil dibuat sebagai tempat untuk perbaikan serta perawatan kendaraan Roda Dua. Pemilik kendaraan dapat membawa kendaraan motornya ke bengkel terdekat dan memberi tahu keluhan tentang kendaraannya pada pakar - pakar otomotif yang ada di bengkel tersebut. Waktu telah menjadi modal utama yang sangat berharga. Perawatan yang kiranya bisa dilakukan sendiri, serta tanpa harus pergi datang ke bengkel dengan membawa kendaraan tersebut, akan sangat membantu sekali, khususnya untuk orang yang awam tentang otomotif dan tidak mempunyai waktu datang ke bengkel menunggu sampai kendaraannya selesai direparasi.

kecerdasan buatan yang mempelajari bagaimana "mengadopsi" cara seorang pakar berpikir dan bernalar dalam menyelesaikan suatu permasalahan, dan membuat suatu keputusan maupun mengambil kesimpulan dari sejumlah fakta yang ada. Dasar dari suatu sistem pakar adalah bagaimana mentransfer pengetahuan yang dimiliki oleh seorang pakar ke dalam komputer, dan bagaimana membuat keputusan atau mengambil kesimpulan berdasarkan pengetahuan itu.

Sampai saat ini sudah ada beberapa hasil perkembangan sistem pakar dalam berbagai bidang sesuai dengan 
kepakaran seseorang misalnya bidang pendidikan, kedokteran maupun bidang yang menyangkut perbaikan kendaraan Roda Dua. Kendaraan Roda Dua merupakan salah satu sarana transportasi yang sering mengalami gangguan atau kerusakan sehingga dengan mengandalkan kemajuan di bidang teknologi dan informasi tersebut.

Dibuatnya aplikasi sistem pakar diagnosa kerusakan pada Kendaraan Roda Dua Jenis Matic Merk Yahama adalah agar dapat mendeteksi jenis kerusakan apa saja yang terjadi terhadap kendaraan yang diperbaiki dan mencari solusi pemecahan masalah terhadap kerusakan tersebut.

\section{RUANG LINGKUP PENELITIAN}

Agar tidak ke luar dari permasalahan yang penulis bahas maka penulis memberikan batasan masalah sebagai berikut :

1. Sistem pakar ini hanya untuk diagnosis Kendaraan Roda Dua Jenis Matic Merk Yahama MIO SOUL.

2. Pembuatan sistem pakar untuk mendeteksi kerusakan pada kendaraan Roda Dua jenis matic merk Yahama mio soul hanya menyangkut kerusakan-kerusakan yang umum terjadi, misalnya: kerusakan pada sistem kemudi, transmisi daya, pengereman dan lainnya.

3. Dalam sistem yang di buat oleh penulis menggunakan Faktor Kepastian (Certainty Factor) dan Runut Maju sebagai penulusuran.

4. Data yang digunakan adalah kendaraan Roda Dua jenis matic merk Yahama Mio Soul.

5. User atau pengguna yang berhak menggunakan aplikasi adalah orang yang mengerti tentang komputer.

\section{BAHAN DAN METODE}

\subsection{Penjelasan Bahan}

Menurut Suparman (2002), Sistem pakar adalah suatu program komputer yang dibangun berdasarkan basis pengetahuan dan aturan (bukan berdasarkan algoritma) dan mengandung pengetahuan dari satu atau lebih pakar manusia mengenai suatu bidang spesifik.

Orang yang terlibat dalam sistem pakar

1. Pakar (Domain Expert) adalah orang ahli yang memiliki pengetahuan khusus, pendapat, pengalaman dan metode serta kemampuan untuk pengaplikasian keahlian tersebut guna menyelesaikan masalah.

2. Perekayasa Sistem (Knowladge Enginer) adalah orang yang membantu pakar menyusun area permaslahan dengan menginterpretasikan dan mengintegrasikan jawaban-jawaban pakar atas pertanyaan yang diajukan, menggambarkan analogi dan menerangkan kesulitan-kesulitan konseptual.

3. Pemakai (User) adalah seseorang yang berkonsultasi dengan system untuk mendapatkan saran yang disediakan oleh system. Pemakai adalah orang-orang yang bukan pakar (Non-Expert) seperti pelajar dan biar juga seorang pakar (Expert) yang ingin meningkatkan kemampuan kepakarannya.
Pembangun system (System Enginer) adalah seseorang yang membuat antarmuka pengguna, merancang bentuk basis pengetahuan dan mengimplementasikan mesin inferensi.

"Otak" Sistem Pakar adalah mesin inferensi, yang dikenal juga sebagai struktur kontrol atau penerjemah aturan. Komponen ini sebenarnya adalah program komputer yang menyediakan metodologi untuk mempertimbangkan informasi dalam pengetahuan dan workplace merumuskan kesimpulan.

\subsection{Model Untuk Menghitung Certinty Factor} Untuk menghitung tingkat keyakinan $(\mathrm{CF})$ dari sebuah rule adalah sebagai berikut:

$$
\begin{aligned}
& \mathrm{CF}[\mathrm{H}, \mathrm{E}]=\mathrm{MB}[\mathrm{H}, \mathrm{E}]-\mathrm{MD}[\mathrm{H}, \mathrm{E}] . \\
& M B\left[h, e_{1} \wedge e_{2}\right]= \\
& \left\{\begin{array}{cc}
0 & M D\left[h, e_{1} \wedge e_{2}\right]=1 \\
M B\left[h, e_{1}\right]+M B\left[h, e_{2}\right] \cdot\left(1-M B\left[h, e_{1}\right]\right) & \text { lainnya }
\end{array}\right. \\
& M D\left[h, e_{1} \wedge e_{2}\right]= \\
& \left\{\begin{array}{cc}
0 & M B\left[h, e_{1} \wedge e_{2}\right]=1 \\
M D\left[h, e_{1}\right]+M D\left[h, e_{2}\right] \cdot\left(1-M D\left[h, e_{1}\right]\right) & \text { Lainnya }
\end{array}\right.
\end{aligned}
$$

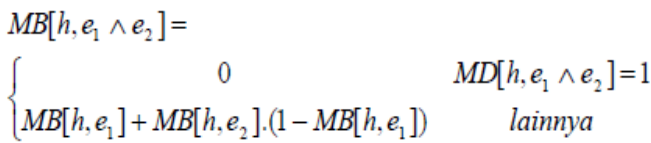

Keterangan

$\mathrm{CF}=$ Certainty Factor dalam hipotesis $\mathrm{H}$ yang di pengaruhi oleh $\mathrm{E}$

$\mathrm{MB}=$ Meansure of Believe, merupakan nilai kenaikan dari kepercayaan hipotesis $\mathrm{H}$ dipengaruhi oleh fakata $\mathrm{E}$

$\mathrm{MD}=$ Meansure of Disbelieve, merupakan nilai kenaikan dari ketidak percayaan hipotesis $\mathrm{H}$ dipengaruhi oleh fakata $\mathrm{E}$

$\mathrm{E}=$ Evidence (Peristiwa atau Fakta )

$\mathrm{H}=$ Hipotesis $($ Dugaan) 


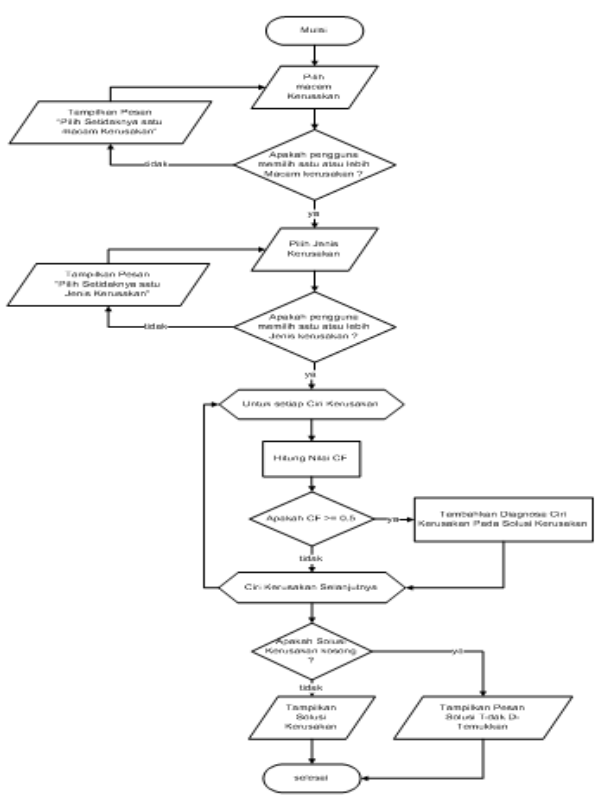

Gambar 1. Flowchart Sistem Pakar

\begin{tabular}{|c|c|c|c|}
\hline \multicolumn{4}{|c|}{ Tabel 1 User } \\
\hline $\begin{array}{l}\text { Nama } \\
\text { Field }\end{array}$ & Tipe & Ukuran & Keterangan \\
\hline Nama & Text & 10 & Nama User \\
\hline Passwd & Text & 8 & Password \\
\hline
\end{tabular}

\begin{tabular}{|c|c|c|c|}
\hline Nama Field & Tipe & Ukuran & Keterangan \\
\hline NoMacam & Text & 4 & $\begin{array}{c}\text { No Macam } \\
\text { Kerusakan }\end{array}$ \\
\hline NoKerusakan & Text & 4 & $\begin{array}{c}\text { No } \\
\text { Kerusakan }\end{array}$ \\
\hline
\end{tabular}

Tabel 3 Tabel Macam Kerusakan

\begin{tabular}{|c|c|c|c|}
\hline Nama Field & Tipe & Ukuran & Keterangan \\
\hline NoMacam & Text & 4 & $\begin{array}{c}\text { No Macam } \\
\text { Kerusakan }\end{array}$ \\
\hline Macam & Text & 75 & $\begin{array}{c}\text { Macam } \\
\text { Kerusakan }\end{array}$ \\
\hline
\end{tabular}

Tabel 4 Kerusakan

\begin{tabular}{|c|c|c|c|}
\hline Nama Field & Tipe & Ukuran & Keterangan \\
\hline NoKerusakan & Text & 4 & $\begin{array}{c}\text { No Macam } \\
\text { Kerusakan }\end{array}$ \\
\hline Kerusakan & Text & 75 & $\begin{array}{c}\text { Jenis } \\
\text { Kerusakan }\end{array}$ \\
\hline Solusi & Memo & - & $\begin{array}{c}\text { Solusi } \\
\text { Kerusakan }\end{array}$ \\
\hline
\end{tabular}

Dimana $t(n)$ adalah waktu cari (second), $b$ adalah waktu yang diperlukan untuk mengawali satu lintas (second), $n$ adalah banyaknya lintas atau silinder yang akan dilewati, dan $s$ adalah waktu mantap hulu tulis baca (second).

\section{RANCANGAN SISTEM Context Diagram}

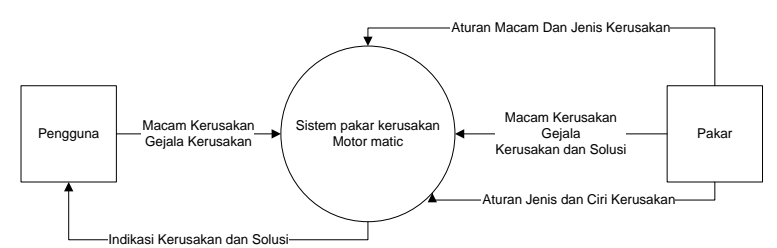

Gambar 2. Context Diagram

Pada gambar merupakan tampilan dari context diagram dimana entitas admin mengirimkan data aturan, macam, ciri, jenis dan diagnosa kerusakan pada sistem. Kemudian entitas pengguna meminta data macam dan jenis kerusakan ke sistem yang nantinya akan menghasilkan ciri dan diagnosa terhadap kerusakan yang dihadapi oleh entitas pengguna.

\section{DFD Level 0}

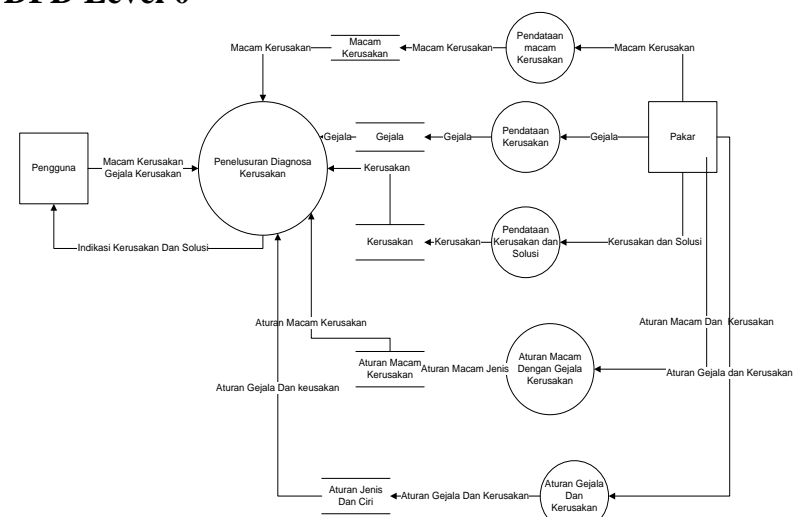

Gambar 3. Data Flow Diagram (DFD) Level 0

Pada gambar merupakan tampilan DFD Level 0 dimana dimulai dari entitas admin mengirimkan data macam kerusakan untuk diproses dan disimpan kedalam data store kerusakan. Entitas admin juga mengirimkan data jenis kerusakan untuk diproses dan disimpan kedalam data store jenis kerusakan. Entitas admin juga mengirimkan data ciri kerusakan untuk diproses dan disimpan dalam data store ciri kerusakan. Entitas admin mengirimkan data aturan macam, jenis dan ciri kerusakan ke system untuk diproses dan disimpan dalam data store aturan macam jenis dan ciri kerusakan. Kemudian entitas pengguna meminta data macam dan jenis kerusakan ke sistem yang nantinya akan menghasilkan ciri dan diagnosa terhadap kerusakan yang dihadapi oleh entitas pengguna. 


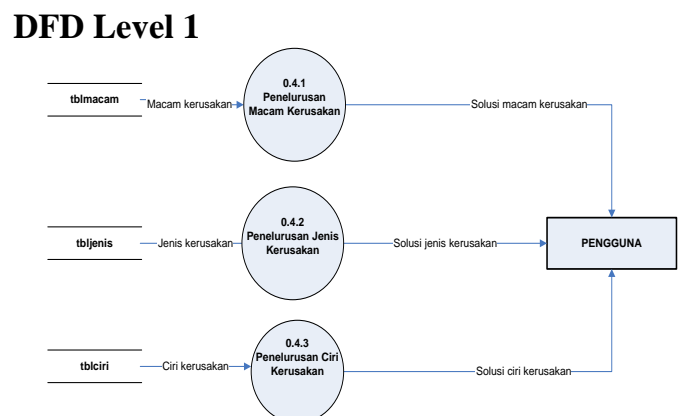

Gambar 4. DFD Level 1

Pada gambar merupakan tampilan DFD Level 1 dimana keseluruhan tabel digunakan untuk proses penelurusan kerusakan kendaraan yang akan menghasilkan solusi terhadap kerusakan yang dihadapi.

\section{IMPLEMENTASI}

\section{Form Login}

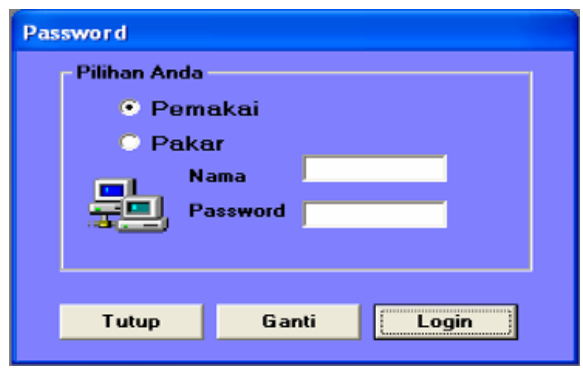

Gambar 5. Form Login

Pada gambar merupakan tampilan Form Login dimana terdiri dari pilihan Pemakai dan Pakar. Jika Benar maka akan dapat masuk kedalam program, jika salah maka tidak akan dapat masuk kedalam program.

\section{Menu Utama}

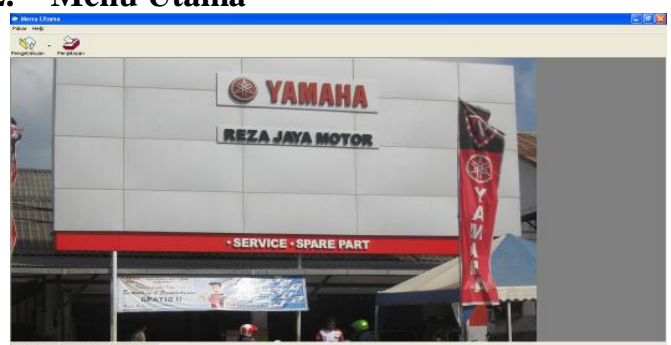

Gambar 6. Form Menu Utama

Pada gambar Tampilan dari menu utama system dimana terdiri dari pilihan pengetahuan dan penjelasan sistem. Sementara menu-menu yang disediakan adalah menu Pakar, dan Menu Help. Menu Pakar berisi sub menu Basis Pengetahuan, Basis Aturan, penjelasan sistem dan sub menu keluar.

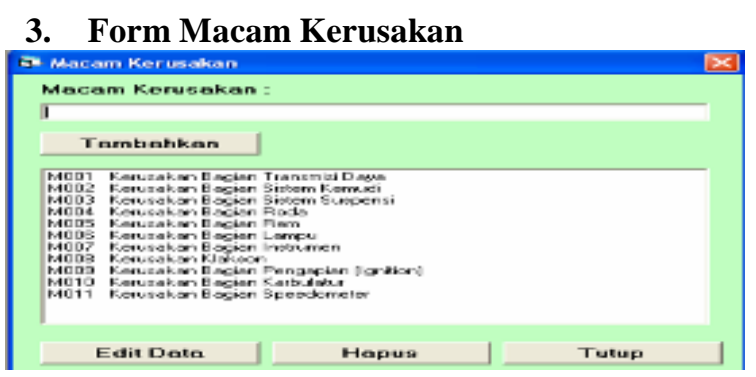

Gambar 7. Form Macam Kerusakan

merupakan tampilan macam kerusakan, yang berisikan data macam kerusakan-kerusakan. Tombol tambah berfungsi untuk menambahkan kerusakan. Tombol edit data berfungsi untuk mengubah data yang ada. Tombol hapus berfungsi untuk menghapus data. Dan tombol tutup berfungsi untuk keluar dari form.

\section{Form Gejala Kerusakan}

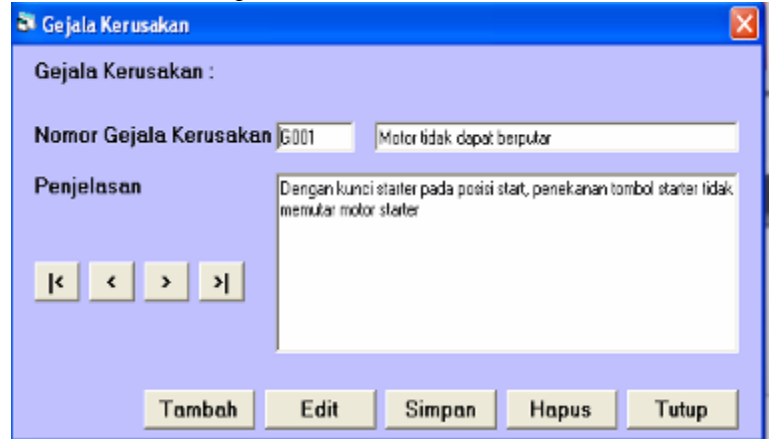

Gambar 8. Form Gejala Kerusakan

merupakan tampilan Form Gejala kerusakan yang terdiri dari nomor kerusakan, gejala kerusakan dan penjelasan. Tombol navigasi berfungsi untuk melihat data sebelumnya, berikutnya, data pertama dan data terakhir. Tombol tambah berfungsi untuk menambah data. Tombol edit berfungsi untuk mengubah data. Tombol simpan berfungsi untuk menyimpan data. Tombol hapus berfungsi untuk menghapus data. Dan tombol tutup berfungsi untuk menutup form.

\section{Form Kerusakan}

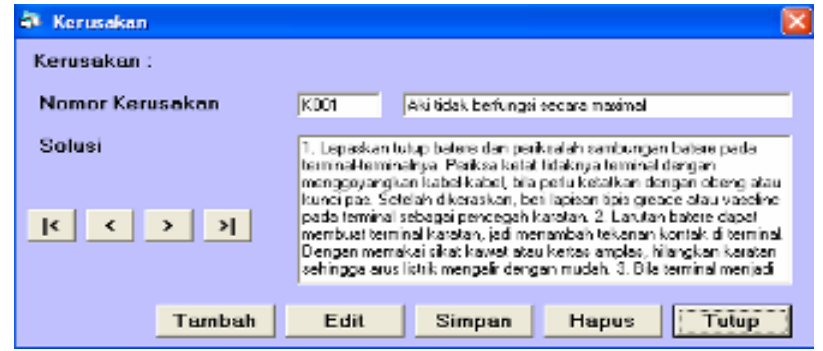

Gambar 9. Form Kerusakan 
merupakan tampilan Form kerusakan yang terdiri dari nomor kerusakan, kerusakan dan solusi. Tombol navigasi berfungsi untuk melihat data sebelumnya, berikutnya, data pertama dan data terakhir. Tombol tambah berfungsi untuk menambah data. Tombol edit berfungsi untuk mengubah data. Tombol simpan berfungsi untuk menyimpan data. Tombol hapus berfungsi untuk menghapus data. Dan tombol tutup berfungsi untuk menutup form.

\section{Form Basis Aturan}

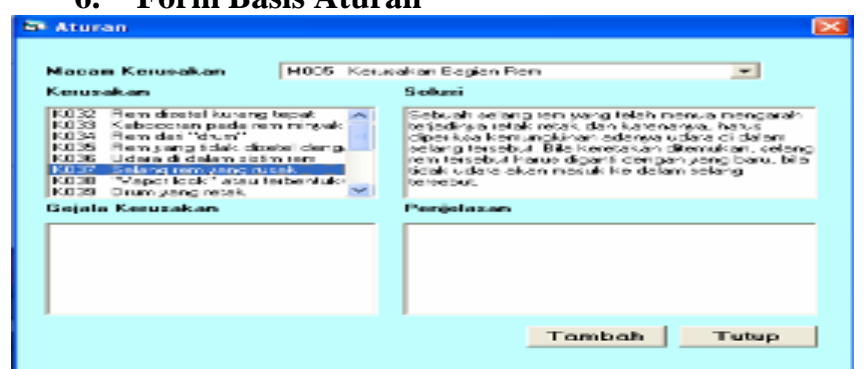

Gambar 10. Form Basis Aturan

merupakan tampilan dari form basis aturan, dimana disini letak pengaturan macam kerusakan, gejala dan kerusakan yang saling berhubungan dengan kerusakankerusakan. Tombol tambah berfungsi untuk menambahkan pengaturan-pengaturan yang ada. Tombol tutup berfungsi untuk menutup form.

\section{Form Tambah Aturan}

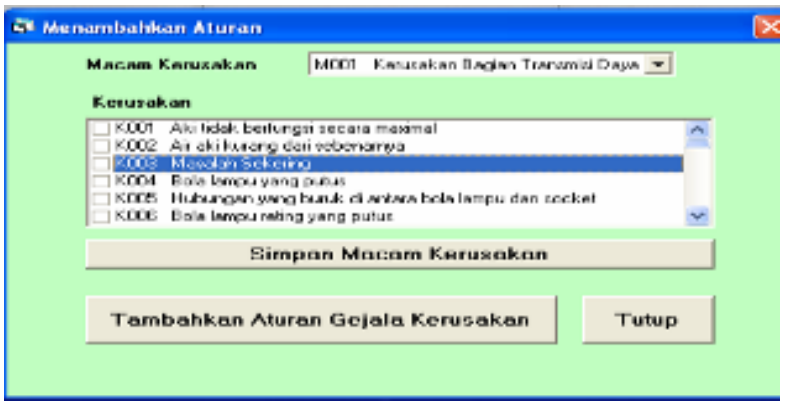

Gambar 11. Form Tambah Aturan

Pada gambar merupakan tampilan Form tambah aturan yang berfungsi untuk menambah atau mengurangi ataupun menghapus pengaturan-pengaturan yang ada. Disini akan ditampilkan macam dan kerusakan yang terhubung dengan macam kerusakan, sehingga memungkinkan user untuk memilih kerusakan lainnya yang memungkinkan untuk menghubungkan dengan macam kerusakan. Tombol simpan berfungsi untuk menyimpan perubahan aturan. Tombol Tambah aturan gejala kerusakan berfungsi untuk menambahkan gejala kerusakan. Tombol tutup berfungsi untuk menutup form.

\section{Form Tambah Ciri Kerusakan}

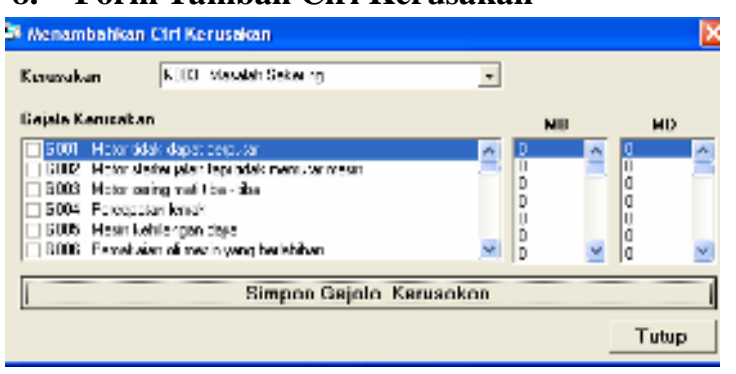

Gambar 12. Form Tambah Ciri Kerusakan

merupakan tampilan Form tambah ciri kerusakan yang berisikan kerusakan, gejala kerusakan, MB dan MD. Tombol simpan gejala kerusakan berfungsi untuk menyimpan gejala kerusakan yang dipilih sesuai dengan kerusakan. Tombol tutup berfungsi untuk menutup form dan kembali pada menu utama.

\section{Form Penilaian Certainty Factor (CF)}

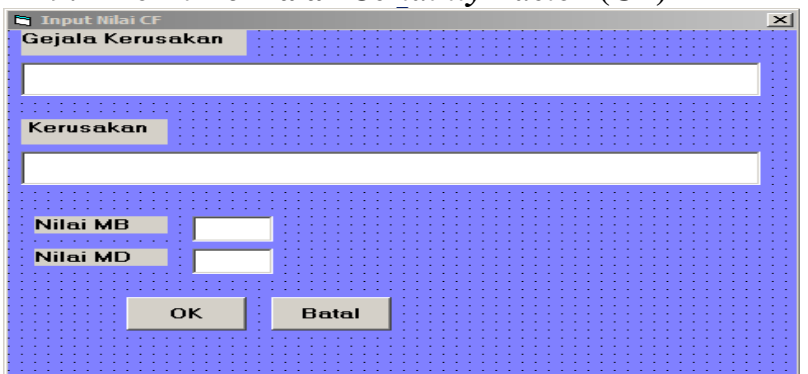

Gambar 13. Form input nilai Certainty Factor

merupakan tampilan Form Certainty Factor (CF) dimana berisikan nilai-nilai dari $\mathrm{CF}$ yang sesuai dengan gejala dan kerusakan yang dialami. Tombol Ok berfungsi untuk menyimpan hasil $\mathrm{CF}$ dan tombol batal berfungsi membatalkan proses nilai dan kembali pada menu utama.

10. Form Penelurusan Gejala Kerusakan

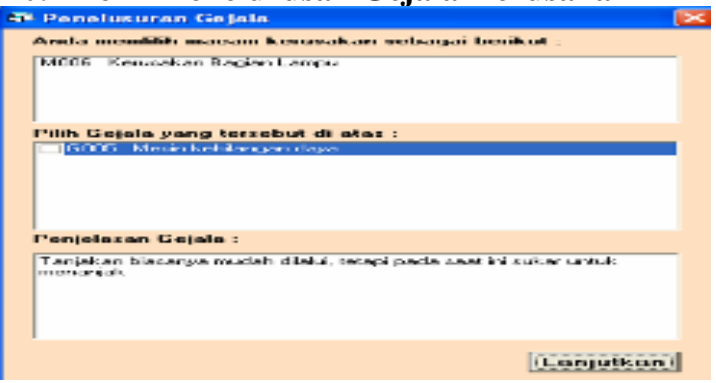

Gambar 14. Form Penelurusan Gejala Kerusakan

Pada gambar merupakan tampilan Form penelurusan gejala kerusakan yang berfungsi untuk memilih gejala kerusakan yang dialami. gejala kerusakan akan muncul sesuai dengan pilihan macam kerusakan. Disini juga akan ditampilkan gejala-gejalannya.

\section{Form Rekaman Data}

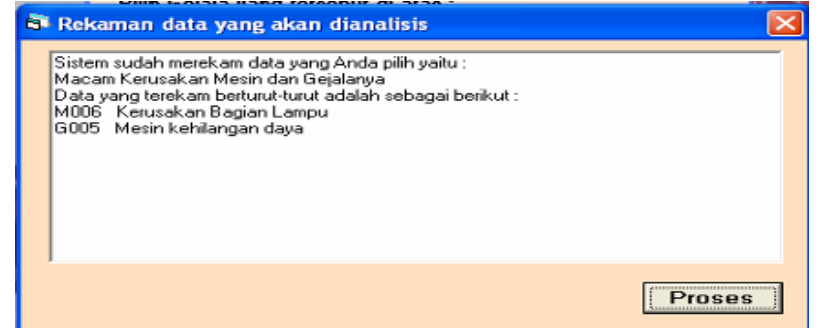

Gambar 15. Form Rekaman Data

merupakan tampilan Form rekaman data macam, jenis dan ciri kerusakan yang telah kita pilih sebelumnya. Tombol proses berfungsi untuk melihat solusi yang ditawarkan oleh sistem. 


\section{Form Solusi Kerusakan}

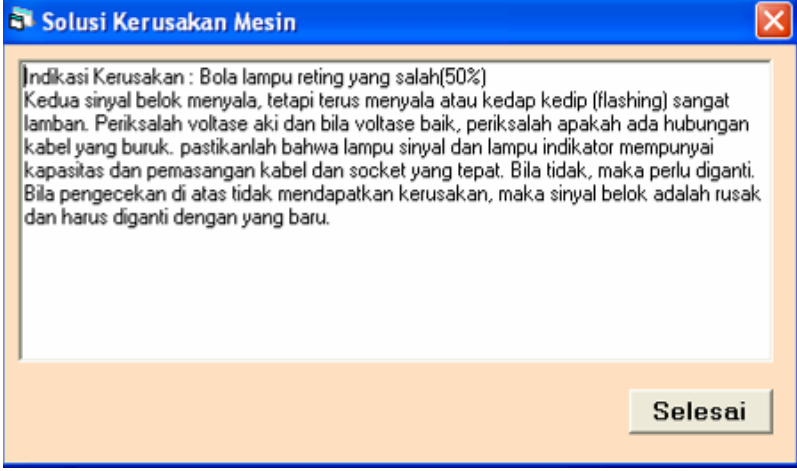

Gambar 16. Form Solusi Kerusakan

Pada gambar merupakan tampilan Form solusi kerusakan yang berfungsi untuk melihat solusi yang ditawarkan oleh sistem terhadap pilihan macam, jenis dan ciri kerusakan yang telah kita pilih sebelumnya. Tombol selesai berfungsi untuk menutup form.

\section{Form Penjelasan Sistem}

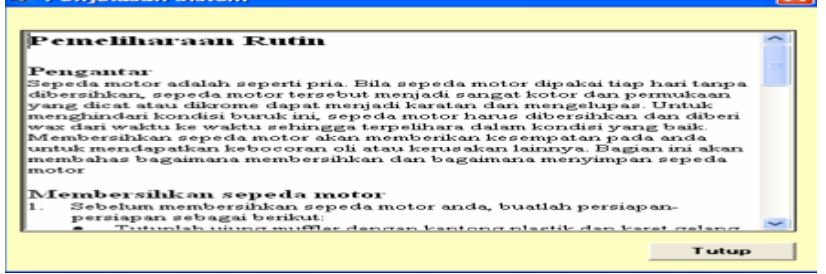

Gambar 17. Form Penjelasan Sistem

merupakan tampilan Form penjelasan sistem yang berisi penjelasan-penjelasan yang berhubungan dengan kendaraan.

\section{KESIMPULAN}

Berdasarkan hasil dari pembahasan dan penjelasan sebelumnya, maka dapat dibuat kesimpulan yaitu :

1. Sistem Pakar Diagnosa Kerusakan Kendaraan Roda Dua Jenis Matic Merk Yamaha yang berbasis komputer merupakan penyelesaian dari masalah yang terjadi saat ini dalam hal proses diagnosis kerusakan pada kendaraan roda dua. Maka dari itu Sistem Pakar yang telah di buat ini diharapkan dapat mempermudah dan mempercepat dalam proses diagnosis kerusakan pada kendaraan roda dua jenis matic.

2. Sistem Pakar Diagnosa Kerusakan Kendaraan Roda Dua Jenis Matic Mio Soul pada Reza Jaya Motor Samarinda yang terkomputerisasi dapat memberikan hasil yang lebih cepat, tepat dan efisien bagi penggunanya khususnya kepada bagian Mekanik yang akan melakukan perbaikan kendaraan roda dua.

\section{SARAN}

Berdasarkan dari kesimpulan-kesimpulan yang telah dikemukakan sebelumnya, maka di memberikan saransaran sebagai berikut :

Hendaknya Sistem Pakar diagnosa kendaraan roda dua jenis matic ini dapat digunakan sebagai acuan maupun bahan rujukan dalam Sistem Pakar berbasis komputer dimasa-masa yang akan datang.

1. Dengan desain program yang ada tidak menutup kemungkinan adanya kekurangan-kekurangan pada program tersebut, maka agar sistem dapat lebih sempurna diharapkan sistem ini dikembangkan lebih lanjut lagi.

2. Untuk yang bermaksud mengembangkan system pakar ini diharapkan lebih memahami informasi yang bisa diserap dari buku atau dari pakar itu sendiri.

\section{DAFTAR PUSTAKA}

Anonim, 2002, Kamus Besar Bahasa Indonesia, edisi ketiga Departemen Pendidikan dan kebudayaan dan balai pustaka, Jakarta.

Anonim, 2007, panduan service Yamaha mio soul.

Arhami, Muhammad, 2005, Konsep Dasar Sistem Pakar, Yogyakarta : Penerbit Andi

Divisi Penelitian dan Pengembangan MADCOMS. 2008, Microsoft Access 2007, Yogyakarta: Penerbit Andi offset

Fathansyah, 2004, Basis Data, Penerbit Informatika, Bandung.

Kristanto, 2003 Andri, Perancangan Sistem Informasi Dan Aplikasinya, Jakarta, Penerbit Gaya Media.

Kusrini, 2006, Sistem Pakar Teori dan Aplikasi, Yogyakarta: Penerbit Andi

Pressman, Roger, 2002, Rekayasa Perangkat Lunak Pendekatan Praktisi (Buku I), Yogyakarta : Penerbit Andi \& McGraw-Hill Book Co.

Suparman, 2002 : Mengenal Artificial Intelegence, Andi Offset, Yogyakarta

Simarmata, Janner, 2010, Rekayasa Perangkat Lunak, Yogyakarta : Andi Offset.

Wahana Komputer Semarang, 2003, Tip \& Trik Pemrograman Visual Basic 6.0, Yogyakarta: Penerbit Andi Offset

Yuswanto, 2003, Pemrograman Visual Basic 6.0, Penerbit Informatika, Bandung. 